\title{
LA CIENCIA DE LA LÓGICA Y EL CONCEPTO HEGELIANO DE ESPÍRITU COMO «NATURALEZA ASUMIDA»
}

\author{
MARTÍN ZUBIRIA \\ Universidad Nacional de Cuyo
}

"Sollte die Logik freylich nichts als leere, todte Gedankenformen enthalten, so könnte in ihr überhaupt von keinem solchen Inhalte wie die Idee, oder das Leben ist, die Rede sein» (Hegel, GW 12, 179, 5-8)

\begin{abstract}
RESUMEN: La doctrina de la Idea, en el final de la Ciencia de la Lógica, se sirve de la noción de «espíritu» para explicar la naturaleza de la Idea misma, cuyas determinaciones lógicas son, a su vez, las determinaciones de lo espiritual. Nos proponemos mostrar en qué medida los pasajes de la doctrina de la Idea referidos al "espíritu» están lejos de poseer un significado episódico.

PALABRAS CLAVE: Hegel; Ciencia de la Lógica; Idea; Concepto; Espíritu.

\section{The Science of Logic and the Hegelian concept of spirit as "assumed nature»}

ABSTRACT: The doctrine of the Idea, at the end of the Science of Logic, uses the notion of «spirit» to explain the nature of the Idea itself, whose logical determinations are, at the same time, spiritual ones. We intend to show in what sense the passages of the doctrine of the ldea referred to the "spirit» are far from having an episodic significance.

KEY WORDS: Hegel; Science of Logic; Idea; Concept; Spirit.

Como es sabido, dentro de la Enciclopedia de las ciencias filosóficas, la filosofía, entregada a la tarea de concebirse a sí misma como "ciencia infinita», articula su saber en la unidad de un proceso trinitario cuyos grandes momentos son: la Lógica, la Naturaleza y el Espíritu. La pregunta por el sujeto de ese proceso único está lejos de resultar enigmática, no bien se ha comprendido que Lógica, Naturaleza y Espíritu son otras tantas determinaciones del Concepto especulativo, siendo este, a su vez, resultado de un saber que se engendra a sí mismo en la forma científica de una «Fenomenología», esto es, de una doctrina cuya materia próxima debemos verla en la manifestación progresiva del mentado Concepto. Esa "Fenomenología», sin embargo, no es la del Concepto, sino la «del Espíritu». ¿Por qué motivo?

Para responder esta pregunta, antes de esclarecer con el propio Hegel la naturaleza del "Concepto especulativo», bastará con recordar que el espíritu es, constitutivamente, saber, ya desde su manifestación más elemental e inmediata en la forma de la «certeza sensible», siendo esta, de suyo, una figura del espíritu, aunque en un sentido impropio todavía, pues el sujeto de tal certeza deberá recorrer 
un largo camino para comprender, de manera científica, que el objeto verdadero del saber, en cuanto saber puro, no es ni un simple «objeto» (conciencia), ni el simple «yo» (autoconciencia), ni la simple «categoría» (razón), sino, precisamente, el "Concepto», término que escribimos de ahora en adelante con mayúscula porque designa un singulare tantum y no el mero "Actus < sic $>$ del entendimiento autoconsciente» $(G W 12,20,12)^{1}$. Pero el saber que realiza su propio Concepto y que se sabe a sí mismo como tal no es sino el espíritu (cf. $G W$ 9, 427, 28-31). Este, vuelto ya "saber absoluto» en el final de la serie de sus figuras sucesivas ("conciencia», "autoconciencia», «razón») —figuras donde no pasa de ser sino una abstracción de sí mismo-, se identifica no ya con la verdad, sino con su certeza absoluta. Y en esta su concreción especulativa, la del Concepto como «lo supremo del pensar» (das höchste des Denkens, GW 12, 17, 2), el Espíritu es el sujeto único del saber desplegado a lo largo de las tres partes de la Enciclopedia.

Pero si la «Fenomenología» es la del Espíritu, por otro lado, el sistema del saber filosófico ya realizado se presenta en la Enciclopedia no de unas «ciencias del espíritu», sino, de manera expresa, de las «ciencias filosóficas». En la articulación unitaria de las mismas, el Espíritu, hallándose inicialmente en el elemento de la interioridad «abstracta» del pensamiento puro (la «Lógica»), se manifiesta sólo como un "en sí» (an sich) en la figura del "Concepto», mientras que la negación especulativa de sí mismo, realizada en el elemento de la exterioridad sensible, se despliega en un ámbito no por vasto menos limitado, ya por el hecho de ser solo «un» reino entre otros: el de la «Naturaleza». Sólo la negación de esta negación permite que el Espíritu aparezca en su figura verdadera y propia, la del Concepto «en sí y por sí», cuyo ser se ve afectado primero, por la limitación de lo puramente subjetivo, y luego por la limitación opuesta, la de lo puramente objetivo. Mediante la superación sucesiva de esas dos formas de finitud, el Espíritu se encuentra por fin consigo mismo y revela lo absoluto de su saber de manera «metódica» en la forma sensible del Arte, en la forma simbólica en la Religión y por último en la forma conceptual en la Filosofía.

Lo cierto es que el Espíritu, aun cuando se despliegue «en y por sí» en su ciencia enciclopédica propia, se manifiesta de manera inequívoca, como tal Espíritu, en la doctrina de la Idea, esto es, en el remate de la «Lógica», tanto en su desarrollo independiente de 1816, como en la versión enciclopédica. A lo largo del desarrollo de la Idea la noción de «Espíritu» aparece una y otra vez, pero ya no como cabría reconocerlo en las determinaciones abstractas del «Ser», de la «Esencia», e incluso del «Concepto» y de la «Objetividad», ya no como un puro «en sí» (an sich) — siendo esta, cuando del Espíritu se trata, una determinación que le es ajena (ungeistig)—, sino como Espíritu «en cuanto tal» (als solcher).

$\mathrm{Si}$, atendiendo a la «cosa» de que se trata, esto, por poco que se lo piense, no

1 Citamos las obras de Hegel por la edición histórico crítica: Georg Wilhelm Friedrich Hegel, Gesammelte Werke, in Verbindung mit der deutschen Forschungsgemeinschaft herausgegeben von der Rheinisch-Westfälischen Akademie der Wissenschaften, erschienen im Felix Meiner Verlag, Hamburg 1968 ss.. La cita indica, tras la sigla $G W$, el número de volumen, a continuación el de la página (sin la abreviatura p.) y luego el de la línea, separados por una coma. Dos números solos entre paréntesis, corresponden a la página y la línea del volumen citado inmediatamente antes. 
podría ser de otra manera, como trataremos de mostrar en lo que sigue, también es verdad que semejante anticipación nos obliga a meditar una vez más acerca de la autonomía relativa de la "Ciencia de la Lógica» y de la «Filosofía del Espíritu» y de sus respectivos límites. Tal es la razón por la que nos hemos propuesto considerar de qué modo el Espíritu se presenta, ya en la «Lógica», y más precisamente en la doctrina de la Idea, bajo su figura propia, esto es, la del «para sí» o el "por sí» (für sich). Pues para anticiparlo ya en este punto, la Idea, según veremos, no se limita a ser el espíritu «en sí»; ello significaría igualarla de manera indebida con el «ser» o con la "esencia», o con el "concepto subjetivo», de los que también cabe afirmar que son el Espíritu «en sí», esto es, en cuanto posibilidad.

En la Enciclopedia, el paso de la Naturaleza al Espíritu no es un tránsito hacia lo radicalmente otro - esto es imposible por la razón que apuntaremos más abajo-, sino un volver del Espíritu en sí mismo $\left(\S 381\right.$, Z.) ${ }^{2}$, tras haberse hallado en la Naturaleza fuera de sí. Hacerse cargo de esta verdad con la debida coherencia obliga a inferir, de manera retrospectiva, que también en el tránsito de la Lógica a la Naturaleza hay un sujeto común, a saber: el Espíritu mismo que, para poder hallarse "fuera de sí», en la mentada Naturaleza, ha debido hallarse antes "en sí»; no de otro modo es como se presenta en la Lógica, comenzando por las determinaciones abstractas del Ser y de la Esencia, para alcanzar luego la concreción lógica del Concepto. «Como determinación diferenciadora del concepto de espíritu <subrayado nuestro > se ha de señalar la Idealidad, esto es, la asunción de lo otro que la Idea, su retornar y haber retornado en sí desde su opuesto, mientras que en la Idea lógica, lo diferenciador es el ser en sí simple (einfaches Insichsein), inmediato, y en la Naturaleza el ser fuera de sí (Außersichsein)». (§ 381, Z.).

Bien se ve que el Espíritu, lejos de ser de manera excluyente el objeto determinado de una de las tres "ciencias filosóficas», es el sujeto de la filosofía en cuanto tal; sujeto que se despliega formalmente siempre de un modo análogo, haciendo valer el principio de la idealidad por el que, desde lo inmediato e indiferenciado, se avanza hacia lo otro, esto es, hacia la negación del momento inicial, para retornar finalmente a él mediante la negación de la negación, en un resultado que es tanto «negatividad absoluta» como "afirmación infinita». Así se comprende, por un lado, que el desarrollo íntegro del Espíritu no sea sino «el propio elevarse de sí mismo hacia su verdad» (Die ganze Entwicklung des Geistes ist nichts anderes als sein Sichselbsterheben zu seiner Wahrheit, ibíd.) y, por otro, que esto mismo pueda afirmarse en idénticos términos tanto de la Naturaleza como de la Lógica o del Concepto.

2 En el caso de la Enciclopedia señalamos con una letra Z., allí donde corresponde, que la cita procede de un Zusatz, esto es, de un «añadido oral» al parágrafo de que se trata, conservado en los apuntes de algunos de los asistentes a las clases de Hegel. No todas las ediciones de la Enciclopedia reproducen los Zusätze. Nosotros hemos tenido a la vista la de la editorial Suhrkamp, Georg Wilhelm, Friedrich Hegel. Werke in zwanzig Bände, Auf der Grundlage der Werke von 1832-1845 neu edierte Ausgabe. Redaktion Eva Moldenhauer und Karl Markus Michel, Francfort del Meno 1970, vols. 8-10. 
Por lo que atañe a la «Ciencia» o «Filosofía del Espíritu», esta tiene por objeto «el Espíritu real»(der wirkliche Geist) o «el Espíritu en cuanto tal» (der Geist als solcher). ¿Y qué es este "Espíritu en cuanto tal»? Hegel lo determina, apelando a la Lógica, como la "Idea real que se sabe a sí misma» (sich selbst wissende wirkliche Idee, § 379, Z.; subrayado nuestro); «Espíritu» del que tanto la Naturaleza como la Idea lógica son sus supuestos en términos de inmediatez y mediación.

«El Espíritu en y por sí no es un simple resultado de la Naturaleza, sino, en verdad, su propio resultado; él se produce a sí mismo a partir de los presupuestos que él se forja, la Idea lógica y la Naturaleza exterior, siendo la verdad tanto de aquella como de esta» (§ 381, Z.).

Pues bien, si para la «Ciencia del Espíritu» su objeto no es el Espíritu sin más, sino el «Espíritu real», ya esta sola determinación permite concluir que el Espíritu, si bien bajo una forma no "real», está presente - habrá que ver de qué modotambién en las otras dos ciencias filosóficas. En abono de esta observación cabe realizar esta otra, complementaria, de sentido inverso: si la primera de las ciencias filosóficas se ve precisada a determinar su objeto supremo, la Idea, como «Idea lógica», ello es porque la misma, siendo, por lo demás, «eterna», también "alienta» en las otras dos partes del sistema. Por de pronto en la Naturaleza, desde cuyo interior la Idea, "o lo que es lo mismo, el espíritu en sí» opera la idealización de aquélla: la asunción del "estar lo uno fuera de lo otro» (Außereinander), porque esta forma de existencia, sujeta a las determinaciones espaciales, se opone a la interioridad de su ser.

Si el Espíritu, por su parte, es «el Concepto realizado», esto es, vuelto "real», entonces nada se opone a que tal determinación se predique de la Idea, siendo ella precisamente el Concepto «adecuado» a sí propio, en tanto se tiene a sí mismo por objeto. En esta unidad de la Idea, en esta su adecuación cabal del Concepto (subjetivo) y de la Objetividad, consiste al mismo tiempo no ya su verdad, sino, además, su libertad. Pero si la Idea es «libre», entonces es Espíritu, cuya esencia (o sustancia) es precisamente la libertad (§ 382). Esto arroja una luz meridiana sobre el carácter "poiético», puesto que productivo, de la ciencia filosófica de la Última Época, porque de lo dicho se desprende que para esta ciencia — ¿para quién si no?- el Espíritu, en virtud del movimiento de autodeterminación que le es propio, resulta ser, en cuanto "productor de su libertad» (ibid., Z.), el productor de su sustancia, i. e., causa sui.

Pero la libertad no se agota en ser autodeterminación; ella es, al mismo tiempo, manifestación, porque el espíritu, determinándose a sí mismo, revela su propio ser. También en este sentido se impone reconocer que la «Idea lógica» es Espíritu, no siendo lo otro que ella, la Naturaleza en la exterioridad de su devenir, sino manifestación de la Idea absoluta, Idea que de una manera tan libre como inmediata pone la Naturaleza "como su mundo» (§ 384).

La revelación del propio ser (Sichoffenbaren) es así una operación constitutiva del Espíritu que se articula en tres fases, pues ella es, primero, el movimiento inmanente del Concepto que culmina en su libre tránsito a la existencia exterior y singularizada; luego, el movimiento por el que el Espíritu asume la relación de exterioridad en que se halla frente a la Naturaleza, donde él aparece como lo puramente interior (y por ende como lo puramente exterior) de la misma; por último, el Espíritu se revela en su verdadera autonomía como el doble movimiento 
por el que pone lo otro que él, el ser, la Naturaleza, en el modo de la presuposición y hace surgir, a la vez, la figura del espíritu infinito, de modo que ya nada podría afirmarse como realmente autónomo frente a él (cf. § 384, Z.)

Lo decisivo es comprender que «el Espíritu es siempre Idea» (§ 385, Z., subrayado nuestro); decisivo porque aquí no hay una determinación puramente abstracta o relativa: «el Espíritu es esencialmente <wesentlich> la Idea en la forma de la Idealidad, esto es, en la forma de la negación realizada de lo finito» (§ 386, Z.).

Todo esto se resume en la división tripartita de la Ciencia especulativa, tal como la ofrece el § 18 de la Enciclopedia:

I. La Lógica, la ciencia de la Idea en y por sí,

II. La Filosofía de la Naturaleza como la ciencia de la Idea en su ser otro,

III. La Filosofía del Espíritu como la de la Idea que retorna sobre sí desde su ser otro.

En esta división del todo del «sistema de la ciencia» es fácil ver que el saber especulativo no conoce más objeto que la Idea. Lo que no puede sorprender, si el mismo Espíritu debe ser concebido por la filosofía «como un desarrollo necesario de la Idea eterna» (Die Philosophie muß den Geist als eine notwendige Entwicklung der ewigen Idee begreifen, $\S 379$, Z.). Sin menoscabo de lo cual, cuando la "Idea eterna» se presenta como tal en la Ciencia de la Lógica, es la noción de "Espíritu», por su parte, la que permite captar y comprender la naturaleza de aquella. ¿De qué modo y con qué consecuencias?

Un primer signo ostensible de que el Espíritu, al margen de que se mencione o no de manera expresa, ha de manifestarse como tal en el desarrollo de la Idea lo brinda la división de la doctrina del Concepto en la Enciclopedia (§ 162), según la cual la Idea, la unidad del Concepto y la Objetividad, es la doctrina «de la verdad absoluta» (der absoluten Wahrheit).

En qué sentido, lo señala la «Observación» al parágrafo con que la Enciclopedia abre la doctrina de la Idea, al negar que esta pueda ser considerada «como idea de una cosa cualquiera, del mismo modo que tampoco el Concepto se identifica con un simple concepto determinado. Lo absoluto es la Idea universal y única que, en cuanto se parte o juzga se particulariza en el sistema de las ideas determinadas, concebido como un movimiento de retorno a la Idea única, esto es, a su verdad. En virtud de este juicio, la Idea es, primero, la sustancia una y universal <la Naturaleza>, pero no bien su realidad se ha desarrollado, ella es sujeto y, por ende, espíritu». (§ 213).

Considerar lo lógico de la Idea como una simple limitación, como una determinación puramente formal y abstracta, es un modo de juzgar propio del entendimiento, porque en ella el Concepto, en cuanto libre, produce su realidad (Wirklichkeit) en el mentado "retorno negativo sobre sí» (negative Rückkehr in sich). Movimiento donde la «subjetividad» (Subjektivität) no es sino otro modo de nombrar el espíritu (Geist).

Este se presenta de manera más determinada, dentro del proceso general de la Idea, tal como se lee una y otra vez en la Ciencia de la Lógica (GW 12, 177, 12/15/35; 
178, 4; 184, 24; etc.), allí donde la Idea misma, tras su manifestación inmediata como «vida lógica», se vuelve «conocer»(Erkennen; cf. Enc. § 222ss.), esto es, «asunción» de aquella vida que, en razón de la finitud inherente a su elemento lógico, esto es, al momento de la singularidad, permanece vinculada con la muerte. En el Conocer, en cambio, la Idea revela ya de manera inequívoca su condición espiritual; porque para explicar la génesis de la «Idea del Conocer» se afirma, como una verdad no sujeta discusión, que de la Idea de la Vida «ha surgido la Idea del Espíritu» <(...) die Idee des Lebens, aus der die Idee des Geistes hervorgegangen, (...). $G W 12,196,30>$. De este modo, en el tránsito de la «Vida» al «Conocer», la doctrina de la Idea lógica anticipa un tránsito análogo: el de la Filosofía de la Naturaleza a la del Espíritu.

La introducción a la «Doctrina de la Idea» se sirve, para caracterizarla, de la noción de «Espíritu», porque la Idea se contrapone por igual a las dos totalidades en que se escinde el Concepto: la particularidad del «objeto mecánico y químico» por un lado, y la singularidad del sujeto carente de espíritu (das geistlose Subjekt, $G W 12,174,37$ ), cuya manifestación inmediata es la Vida, por otro; sujeto que no es propiamente Espíritu por ser consciente sólo de lo finito y por permanecer ajeno todavía a su verdadero ser. En ninguna de las mentadas totalidades el concepto existe «en su forma propia y libre» $(175,2)$. Para elevarse por sobre la Vida, su realidad ha de identificarse con su propia forma, liberada ya en el elemento de la universalidad (cf. 192, 16ss.). Por ello el Concepto y, con él, el Espíritu, sólo es verdadero en cuanto Idea, siendo esta última la «unidad del Concepto consigo mismo» $(175,12)$, porque aquel concepto que no se tuviese a sí propio por su realidad, «sería el espíritu inerte, privado de espíritu, un objeto material» (ibíd.).

La distinción entre el espíritu consciente sólo de lo finito y el propiamente tal se relaciona, hacia el final de la Introducción a la doctrina de la Idea, con los tres momentos de su desarrollo, conviene a saber: «Vida», "Conocer» e «Idea absoluta». Porque el proceso del conocer finito (y lo mismo ocurre con el obrar) puede concebirse de dos modos: o bien como un movimiento por el que la universalidad del concepto - la del sujeto mismo del conocer - se vuelve totalidad, objetividad perfecta por la síntesis del Concepto, en cuanto pura forma (puro saber), consigo mismo como materia del conocer, o bien como un movimiento por el que «el espíritu finito, esto es, subjetivo (der endliche, das ist, der subjective Geist), forja para sí el supuesto de un mundo objetivo» (178, 7s.), lo presupone o pone por anticipado (setzt voraus), así como ya la Vida ha presupuesto en relación consigo el todo del objeto lógico. Pues bien, el Conocer, la Idea en cuanto espíritu finito, es la actividad ideal que responde al impulso inmanente de asumir la Vida y negarle así su condición de «supuesto».

Pero, en un tercer momento, tras la «Vida» y el «Conocer», «el Espíritu reconoce la Idea como su verdad absoluta, (...) la idea infinita (...) que es el saber absoluto de sí misma» (178, 12-14; subrayado nuestro). Alcanzado este punto cabe observar: primero, que este Espíritu, capaz de un reconocimiento semejante, ha cobrado conciencia de su propio ser, al haber dejado atrás el carácter «subjetivo» de un saber vinculado sólo con lo finito; y después, que la Idea, al superar, por un lado, la finitud de su inmediatez en cuanto "Vida» y, por otro, la de la negación primera de esa inmediatez en cuanto "Conocer», se vuelve «infinita» o «absoluta», siendo libre en esa su autodeterminación, porque toda la «lógica subjetiva» es el «reino de la 
libertad» $(15,35)$. Pero esto significa que la Idea, enteramente transparente para sí misma, es un absoluto saber de sí y, por ello mismo, "Espíritu».

Sólo que si la Vida, según su «consideración lógica» $(180,6)$, no debe confundirse con la vida «de la Naturaleza» $(180,11)$, ni con «la del Espíritu» $(180,27)$, otro tanto ocurre con este último que, en cuanto «Idea», sólo puede ser objeto de una consideración estrictamente lógica. Esta lo mantiene fuera del círculo de la «Vida», el de la manifestación inmediata de la Idea. En efecto, es necesario que sobrevenga «la muerte de esta vida» para que, en la Idea del Conocer, la Ciencia de la Lógica reconozca «el surgir del Espíritu»(das Hervorgehen des Geistes, 191, 26).

Este se manifiesta o se revela (cf. Enc. § 383), pues ya el Concepto mismo es manifestación (Manifestation, GW 12, 230, 27), desde la determinación lógica que le es propia: la universalidad que, siendo concreta, es relación de sí consigo. Y no es sino por ello, por el hecho de tener en la universalidad o en el concepto su principio, que la Idea del Conocer, a diferencia del conocer inmediato, ignora aquella larga serie de formas de la actividad cognoscitiva que la «Filosofía del Espíritu» caracteriza como propias del espíritu subjetivo en cuanto alma (Antropología) y conciencia (Fenomenología del Espíritu; Enc. §§ 387-439). El Conocer, en la esfera de la Idea, pertenece al orden de la actividad «racional» sensu stricto; ahora bien, este término, el de "racional», en cuanto se identifica con lo especulativo, esto es, con la identidad de determinaciones opuestas (cf. §§ 45 y 82), designa una propiedad fundamental del Espíritu. Y este, a la luz de la «Idea del Conocer», se define como «la unidad absoluta de los opuestos en el Concepto» ( $G W 12,192,32)$.

La actividad «ideal» del Conocer determina el proceso de la Idea en el momento mediador de su "para sí», cuando ella «se tiene a sí misma por objeto», de tal modo que su existencia, la determinación de su ser (Daseyn), ha acabado por purificarse en la forma de esta diferencia simple por la que ella permanece cabe sí misma" (192, 20). El pensar, la autoconciencia, el espíritu mismo, representan concreciones o "determinaciones» (Bestimmungen) del "para sí» de la Idea. Lo que aquí debe subrayarse, en relación con nuestro cometido, es que esta Idea, la Idea del Conocer, «es ya el Espíritu» (ist nun der Geist, 197, 3), con la salvedad anteriormente apuntada de que en la Lógica el Espíritu se halla muy lejos de «la oscura región» (die dunkle Region, 197, 25) de su existencia anímica o meramente consciente, donde, en consonancia con su finitud, se ve sometido a toda suerte de influjos, sidéreos y terrestres. «Muy lejos», porque la Idea del Espíritu, lo mismo que la Idea de la Vida, pertenecen, en cuanto «objetos lógicos», al ámbito «de la ciencia pura» (der reinen Wissenschaft, 198, 26).

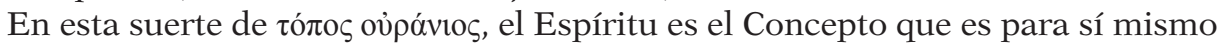
su propio contenido o, en otros términos, la Idea en su «subjetividad»y, con ello, todavía en su finitud. Pero la «Idea del Conocer», siendo un proceso supeditado a su realización, es, por de pronto, sólo una meta, un fin $(Z w e c k, 198,38)$ que se alcanza, gracias al conocer mismo, en la identidad del Concepto con su objeto, sea que este se le presente en la figura de «lo verdadero» (Idea teórica), o bien en la figura «superior» (höher, 231, 25) de «lo bueno» (Idea práctica).

Pero la Idea del Conocer no es sólo un fin que debe realizarse sino, al mismo tiempo, el impulso orientado de suyo hacia esa realización: el impulso del Concepto (Trieb des Begriffes, 201, 25). Una y otra vez la doctrina de la Idea insiste en señalar la condición siempre finita del Conocer (200, 36ss.; 201, 29; 209, 24; cf. 178, 1 y 
4), que no por ser racional es ya especulativo $(201,30)$. ¿Qué conocer es entonces el conocer especulativo? Porque es claro que la Idea misma del Conocer queda asumida y, por lo mismo, negada, en la «Idea absoluta». En el «sistema de la ciencia» la palabra «especulativo» determina no sólo el momento del conocer o de la forma, sino también el del contenido, cuando este último presenta en una unidad concreta determinaciones opuestas cuya verdad el entendimiento sólo reconoce al considerarlas de manera separada. Ese contenido especulativo, designado por la conciencia religiosa como «lo místico»(das Mystische, Enc. § 82, Z.), es para la conciencia filosófica «lo racional»(das Vernünftige, ibíd.).

Pero, para volver al Conocer, su condición especulativa se muestra en la unidad de todos los momentos articulados en una ciencia, la Lógica, que sólo en la Idea absoluta llega a captar su propio concepto $(G W 12,252,33$ s. $)$. Es esta ciencia en el movimiento unitario de su desarrollo sistemático la que explica cómo el Conocer finito así como se hace presente en su propio seno, así también acaba asumido en la «Idea absoluta».

Si nuestro propósito se limitase a considerar aquellos pasajes de la «ciencia lógica» en que la noción de "Espíritu» se emplea para esclarecer la doctrina de la Idea, bastaría con lo dicho para dar tal propósito por cumplido, pues, por mucho que esto pueda asombrarnos, esa noción no vuelve ya a presentarse en el capítulo consagrado a la «Idea absoluta». Y sin embargo, siendo esta última, en cuanto concepto libre e infinito, «el Principio de la Filosofía» y el fundamento único sobre el que descansa todo su contenido (229, 26s.), ¿cómo no ver en ella, en sus momentos constitutivos, la realidad del Espíritu, cuya «Idea» ha sido determinada ya como «objeto lógico» $(198,25)$ ?

Porque si la Naturaleza en su propia esfera, como el Espíritu en la suya, es un modo diferenciado de presentar la existencia (Daseyn) de la Idea absoluta (cf. 236, 24 s.), en ningún caso cabría atribuir a la Naturaleza lo que se predica de la Idea absoluta, conviene a saber, que esta última es «el objeto único y el único contenido de la filosofía» (der einzige Gegenstand und Inhalt der Philosophie, 236, 21). Esto vale, sin embargo, ad pedem litterae, no sólo para la Idea absoluta, sino también para el Espíritu, porque sólo en relación con él se comprende el famoso dictum que, referido a la Idea absoluta, cierra la sentencia que acabamos de citar, aquello de que: «Todo lo demás es error, turbiedad, opinión, afán, arbitrariedad y caducidad; la Idea absoluta sola es ser, vida imperecedera, verdad que se sabe a sí misma y es toda verdad» $(236,17-20)$. Verdad concebida por la Lógica como «el llegar hacia sí mismo» (das Zu-sich-selbst-kommen, 251, 38) mediante la negación metódica de la inmediatez.

Pero esto no es todo. Que la «Idea absoluta» es Espíritu también lo dice el hecho de que la Lógica la identifique, al exponerla en su movimiento inmanente, con «la Palabra originaria» (el subrayado es nuestro) que, siendo exteriorización, es a la vez su negación, porque el elemento de tal Palabra es «el pensamiento puro, donde la diferencia, no siendo todavía un ser otro, es para sí absolutamente transparente y se mantiene como tal» (237, 6-11). Nada hay para el Espíritu que sea cabalmente otro: Ein durchaus Anderes ist für den Geist gar nicht vorhanden (Enc. § 377, Z.).

Es por esta razón que la Naturaleza no puede ser considerada como inmediatez radical o incondicionada, sino siempre como inmediatez mediada, del mismo modo que el comienzo de la Lógica, el «Ser», también es inmediatez mediada, puesto 
que inmediatez en la esfera de la Ciencia, esto es, en el elemento del Saber. Y es también por esta razón que no cabe simplificar la noción de Espíritu, entendiéndolo sólo como "Naturaleza asumida». Porque es el mismo Espíritu quien, para poder asumirla, la presupone (cf. Enc. $§ 441$ y su añadido oral $<Z$. $>$ ) y en consecuencia él no puede ser sólo resultado, sino también "principio». Principio, por lo demás, que ya en el «reino de las sombras» de la Lógica acredita esa su condición de resultado, porque ni en la esfera del Ser, ni en la de la Esencia, y ni siquiera en la del Concepto, sea este «subjetivo» u «objetivo», sino sólo en la de la Idea se lo reconoce como tal principio.

El proceso de la Idea absoluta es su vida, una actividad inteligible, puesto que ordenada o «metódica», al punto de identificarse con el Método mismo, que no sólo es la "sustancia», sino también el sujeto o el «alma» $(G W 12,238,15)$ de lo sabido por él y cuyo movimiento no es sino el del Concepto $(238,6)$ que, al tenerse a sí mismo por objeto y saberse por ende como «lo absoluto» $(238,3)$, merece, en virtud de su propia naturaleza lógica, ser reconocido como «divino» (göttlich, 253, 5). Y este Concepto divino no debe aguardar a la «Filosofía del Espíritu» para hallar «el supremo concepto de sí mismo» $(253,33)$, porque ya la Lógica alcanza esa meta.

La actividad de este absoluto que, animado por la libertad del Concepto se identifica con el "yo» $(198,32)$ —el Concepto mismo «no es otra cosa que yo o la autoconciencia pura» $(17,8)$ - posee la forma de la autodeterminación; gracias a ella, la universalidad del comienzo revela, por un lado, su abstracción y, por otro, que su resultado o su verdad no es solo «lo singular» $\mathrm{y}$ "concreto» de un "sujeto» $(248,15)$, sino, para decirlo con una expresión que conviene sólo al Espíritu, al sujeto espiritual, "personalidad pura» (reine Persönlichkeit, 251, 11; cf. 236, 13). Un yo que presenta, al margen de sus diferencias (cf. H. Boeder, Topologie der Metaphysik, Friburgo/Múnich 1980), epocales, el rasgo teológico fundamental del Principio, tanto de la Época Primera como de la Época Media, puesto que «en sí (mismo) todo lo abarca y mantiene» (Alles in sich befaßt und hält, 251, 12).

Por eso el Espíritu puede reconocer en la Idea su verdad absoluta; en la Idea infinita, que en cuanto incondicionado saber acerca de sí misma $(178,14)$, no es sino la realidad lógica del Espíritu en cuanto tal. Porque la Lógica es la figura del Espíritu que es sólo en sí, la Naturaleza la figura del Espíritu que se halla fuera de sí, y el Espíritu la del Espíritu mismo en cuanto ha retornado sobre sí mismo, en cuanto es en y por sí. (Enc. § 381, Z.).

En qué medida lo expuesto nos coloca ante el antiquísimo e insuperable abismo que a título de escándalo siempre renovado mantiene la Metafísica occidental, también en la posición de Hegel, apartada del resto de los saberes humanos, es algo que querríamos considerar en otra ocasión.

Universidad Nacional de Cuyo. Conicet

Martín ZuBIRIA

martinzubiria.t@gmail.com

ORCID iD: https://orcid.org/0000-0001-7197-6703

[Artículo aprobado para publicación en diciembre de 2016] 